\title{
Multidrug-resistant Intestinal Staphylococcus aureus among Self-medicated Healthy Adults in Amassoma, South-South, Nigeria
}

\author{
Adebola Onanuga and Tarilate C. Temedie \\ Department of Pharmaceutical Microbiology and Biotechnology, Faculty of Pharmacy, \\ Niger Delta University, Wilberforce Island, Bayelsa State, Nigeria
}

\begin{abstract}
Multiple antibiotic resistant Staphylococcus aureus is one of the common causes of severe nosocomial infections, and the gastrointestinal tract is an important source of its transmission. This study assessed the previous usage of antibiotics by healthy adults (university students and villagers) in Amassoma, Nigeria, and investigated the antimicrobial resistance patterns of their intestinal $S$. aureus isolates. A questionnaire was used for evaluating the previous usage of antibiotics by the volunteers. Stool samples were collected and cultured, and $S$. aureus isolates were confirmed using standard microbiological protocols. Their antimicrobial resistance patterns were determined using disc-diffusion and agar dilution techniques. In total, $54(45.0 \%)$ volunteers used antibiotics on self-medications, and the practice was significantly higher $(\mathrm{p}=0.01)$ among the villagers than among the students. The level of judicious use of prescribed antibiotics was significantly higher $(\mathrm{p}=0.003)$ among the students than among the villagers. Thirty-eight $(31.7 \%)$ healthy adults were colonized with intestinal $S$. aureus. The percentages of resistance of the isolates to some antibiotics were as follows: ampicillin-68.4\%, doxycycline- $60.5 \%$, cefoxitin-34.2\%, vancomycin-36.8\%, erythromycin-34.2\%, and gentamicin-5.3\%. Twenty-five (65.8\%) of the isolates were multidrug-resistant. The need for sound education on the appropriate use of antibiotics and the importance of proper personal hygiene as means of controlling the spread of bacterial antibiotic resistance are highlighted. Thus, effective strategies in these areas are strongly recommended.
\end{abstract}

Key words: Antimicrobial agents; Drug resistance, Microbial; Gastrointestinal tract; Self-medication; Staphylococcus aureus; Nigeria

\section{INTRODUCTION}

Staphylococcus aureus, the golden cluster seed, is a spherical bacterium frequently found in the nose, throat, intestine, vagina, and skin of human body (1). It is a pathogen of greater concern because of its ability to cause a diverse array of life-threatening infections and its capacity to adapt fast to the different environmental conditions $(2,3)$. These features have made infections of $S$. aureus increasingly difficult to treat because of the fast rate at which it develops resistance to common antimicrobial agents.

Correspondence and reprint requests should be addressed to:

Dr. Adebola Onanuga

Department of Pharmaceutical Microbiology and

Biotechnology

Faculty of Pharmacy, Niger Delta University

Wilberforce Island, Bayelsa State

Nigeria

Email: adebolaonanuga@yahoo.co.uk
Multiple antibiotic resistance is a major health concern in the treatment of staphylococcal infections, especially infections of methicillin-resistant $S$. aureus (MRSA) which occurs due to the extensive use of antimicrobial agents, coupled with the transmission of an appreciable proportion of the organism by person-to-person contacts (4). Hence, effective control of antibiotic use and prevention of the transmission of these strains are essential to eradicate this infectious organism.

The gut is an important habitat of parasites and bacteria which can be transmitted through objects contaminated with faeces, indicating the importance of faecal-oral transmission in humans, which can lead to mild or severe diseases in susceptible individuals or when found in sterile sites of the body (5). The presence of staphylococci in stools has been recognized as an important pathogen responsible for antibiotic-associated diarrhoea in humans (6). Reports of recent studies are also implicating the 
gut as an important reservoir of antibiotic-resistant S. aureus strains $(7,8)$.

Most studies on S. aureus have so far been conducted on samples from the nose and throat but only a very few detailed studies on its colonization of the gut have been reported. Thus, there is a need for more studies on $S$. aureus from the gut, as an important reservoir of multiple antibiotic-resistant bacterial strains, especially in developing countries where the control of antibiotic use is inadequate. We report here the prevalence of multidrug-resistant faecal $S$. aureus isolates from healthy inhabitants in Amassoma, Nigeria.

\section{MATERIALS AND METHODS}

\section{Study subjects}

In total, 120 subjects comprising an equal number of villagers and students of the Niger Delta University, Wilberforce Island, Amassoma, Bayelsa state, Nigeria, were randomly recruited into the study for three months from March 2009. Amassoma is a very small village in Bayelsa state, south-southern Nigeria, where the new growing state university exists. Trading, farming of crops, and fishing are the occupations of the villagers.

Willingness of the subjects to participate in the study was a strong criterion for the study. The volunteers gave informed consents by providing demographic data and a completed questionnaire on the evaluation of their previous use of antibiotics. They were not on any antibiotic for at least two weeks at the time of the sampling nor had been admitted to any hospitals in the last one year before the survey. They were aged 15-35 years.

\section{Sampling and isolation of S. aureus}

Sterile cotton swabs were given to the volunteers to deep into their freshly-produced faeces and return into the swab's case. These stool samples were collected from the volunteers within 24 hours and transported within an hour to the laboratory in iced packs, where these were inoculated directly onto prepared sterilized mannitol salt agar (MSA) plates (Oxoid, UK) and streaked before incubated at $37^{\circ} \mathrm{C}$ for 24 hours.

\section{Identification of S. aureus}

S. aureus was identified and differentiated from related organisms based on the colony morphology on the MSA plates. Two discrete yellow colonies on each of the MSA plates were subcultured on sterile nutrient agar (Oxoid, UK) slants aseptically and incubated at $37{ }^{\circ} \mathrm{C}$ for 24 hours. The proliferated organisms were characterized by Gram stain- ing, productions of catalase, DNase, and coagulase (using human plasma). The organisms that were Gram-positive clustered-shaped cocci, positive to catalase, DNase and coagualse tests were confirmed as $S$. aureus. These were stored on slant nutrient agar at $4{ }^{\circ} \mathrm{C}$ and were used for antibiotic-susceptibility testing.

\section{Antibiotic-susceptibility testing \\ Agar diffusion method (zone of inhibition measurement)}

Each isolate of $S$. aureus was standardized using colony suspension method, and the strain's suspension was matched with $0.5 \mathrm{McFarland}$ standards to give a resultant concentration of $1.5 \times 10^{8} \mathrm{cfu} / \mathrm{mL}$ (colony-forming unit per millilitre) (9). The susceptibility testing of commonly-used antibiotics was determined using the modified Kirby-Bauer diffusion technique by swabbing each of the MuellerHinton agar (Oxoids U.K) plates with the resultant saline suspension of each strain, and the following six antibiotic discs from Oxoids, UK, were placed on the plate after 20 minutes of inoculation: cefoxitin $30 \mu \mathrm{g}$ (as a substitute for methicillin) (9), gentamicin $10 \mu \mathrm{g}$, ofloxacin $5 \mu \mathrm{g}$, ciprofloxacin $5 \mu \mathrm{g}$, doxycycline $30 \mu \mathrm{g}$, and trimethoprim/sulphamethoxazole (co-trimoxazole) 1.25/23.75 $\mu$ g (10). The plates were then allowed to stand for at least 30 minutes before incubated at $30^{\circ} \mathrm{C}$ for 24 hours to favour the growth of any methicillin-resistant strains (11). The diameter of the zone of inhibition produced by each antibiotic disc after incubation was measured and interpreted using the zone diameter interpretative standards of the Clinical and Laboratory Standard Institute (CLSI) (9).

\section{Agar dilution method (MIC test)}

Standardized solutions of six other commonly-used antibiotics-vancomycin (Novaplus, USA), ampicillin (Merck, Germany), erythromycin (Merck, Germany), chloramphenicol (Merck, Germany), amoxicillin-clavulanicacid(augmention)(Glaxowellcome, UK), and cefuroxime (Glaxowellcome, UK)-were aseptically prepared. These solutions were used for preparing Mueller-Hinton agar plates of breakpoints of varying CLSI minimum inhibitory concentrations (MICs): vancomycin 2-12 $\mu \mathrm{g} /$ $\mathrm{mL}$, cefuroxime $8 \mu \mathrm{g} / \mathrm{mL}$, ampicillin $0.25 \mu \mathrm{g} / \mathrm{mL}$, erythromycin $0.5 \mu \mathrm{g} / \mathrm{mL}$, chloramphenicol $8 \mu \mathrm{g} /$ $\mathrm{mL}$, and amoxicillin-clavulanic acid (augmentin) $4 / 2 \mu \mathrm{g} / \mathrm{mL}$. The plates were spot-inoculated with each strain's standardized suspension and incubated at $30{ }^{\circ} \mathrm{C}$ for 24 hours (11). Strains that showed growth on each of the antibiotic agar plate were regarded as resistant to the antibiotic using the CLSI breakpoint standards (9). 


\section{Statistical analysis}

Frequencies were obtained, and percentages were calculated for the study variables. The demographic characteristics were compared using the chi-square test (two-tailed) and using the SPSS software (version 15). All reported $\mathrm{p}$ values were two-sided, and $\mathrm{p}$ value of less than or equal to $0.05(\mathrm{p} \leq 0.05)$ was considered significant.

\section{RESULTS}

\section{Analysis of questionnaire}

Copies of the questionnaire were retrieved from all the study subjects. Twenty-nine (24.2\%) of them were aged 15-19 years, 65 (54.1\%) were aged $20-25$ years, and $26(21.7 \%)$ were aged above 25 years. Fifty-four (45\%) of the subjects (students and villagers) used antibiotics on self-medications, of whom 34 (63\%) were villagers while the remaining 20 (37\%) were students (Table 1). The observed difference in the use of antibiotics between the two groups was significant $(\mathrm{p}=0.01)$. Twenty-six (43.3\%) students and 32 (53.3\%) villagers used antibiotics for reasons other than treatment of diseases (Table 2), the difference of which was not significant $(\mathrm{p}=0.273)$. Twenty-five $(41.7 \%)$ students and $10(16.7 \%)$ villagers judiciously used their prescribed antibiotics (Table 3), the difference of which furoxime, augmentin, ciprofloxacin, ofloxacin, and gentamicin. The differences observed in bacterial resistance to various antimicrobial agents between the two groups of subjects were not significant (p>0.05) (Table 5). The antimicrobial resistance patterns of the isolates from females and the isolates from males were compared, and a marked difference was observed only in doxycycline $(\mathrm{p}=0.013)$, with the females having the highest doxycyclineresistant isolates. MRSA (resistance to cefoxitin) was detected in 13 (34.2\%) of the 38 isolates, all of which were resistant to three or more agents tested. Isolates with reduced susceptibility to vancomycin (MIC >4 $\mu \mathrm{g} / \mathrm{mL}$ ) were 14 (36.8\%), of which eight were MRSA.

\section{Multidrug resistance}

Multiple drug resistance in this study of healthy volunteers was taken as resistant to three or more antimicrobial drugs, and 25 (65.8\%) of the isolates were multidrug-resistant. About one-forth (23.7\%) of the isolates were resistant to four drugs of different resistance combinations. Ampicillin was the most frequently-occurring antibiotic in all the patterns of resistance combinations while co-trimoxazole, doxcycline, and chloramphenicol resistance combinations occurred in only two isolates, and the remaining combinations were all different. The

\begin{tabular}{|c|c|c|c|c|c|c|c|}
\hline \multirow{2}{*}{ Type of use } & \multicolumn{2}{|c|}{ Students $(n=60)$} & \multicolumn{2}{|c|}{ Villagers $(n=60)$} & \multicolumn{2}{|c|}{ Total $(n=120)$} & \multirow{2}{*}{$\mathrm{p}$ value } \\
\hline & No. & $\%$ & No. & $\%$ & No. & $\%$ & \\
\hline $\begin{array}{l}\text { Use of antibiotics on } \\
\text { self-medications }\end{array}$ & 20 & 33.3 & 34 & 56.7 & 54 & 45.0 & 0.01 \\
\hline $\begin{array}{l}\text { Use of antibiotics } \\
\text { on doctor's } \\
\text { prescriptions }\end{array}$ & 40 & 66.7 & 26 & 43.3 & 66 & 55.0 & 0.01 \\
\hline
\end{tabular}

was highly significant $(\mathrm{p}=0.003)$. The distribution of the antimicrobial agents used on self-medication by the subjects is shown in the Figure.

\section{Prevalence of S. aureus}

In total, 38 (31.7\%) isolates of $S$. aureus were detected from 120 stool samples screened, with 18 (30.0\%) from the villagers and 20 (33.3\%) from the students (Table 4). The observed differences in the yield of the organism between the two groups of subjects and between their sexes were not significant $(\mathrm{p}>0.05)$.

\section{Antimicrobial resistance profille}

The isolates generally showed high resistance to ampicillin, doxycycline, co-trimoxazole, erythromycin, and chloramphenicol. However, low levels of resistance were exhibited by the isolates to ce-

\begin{tabular}{|c|c|c|c|c|}
\hline \multirow[t]{2}{*}{ Reason } & \multicolumn{2}{|c|}{$\begin{array}{l}\text { Students } \\
\quad(n=60)\end{array}$} & \multicolumn{2}{|c|}{$\begin{array}{c}\text { Villagers } \\
(n=60)\end{array}$} \\
\hline & No. & $\%$ & No. & $\%$ \\
\hline $\begin{array}{l}\text { Without any } \\
\text { reason }\end{array}$ & 0 & 0.0 & 4 & 6.7 \\
\hline $\begin{array}{l}\text { Prevention } \\
\text { of infection } \\
\text { only }\end{array}$ & 10 & 16.7 & 17 & 28.3 \\
\hline $\begin{array}{l}\text { Treatment of } \\
\text { diseases only } \\
\text { Both } \\
\text { prevention } \\
\text { and treatment }\end{array}$ & 34 & 56.7 & 28 & 46.7 \\
\hline
\end{tabular}

The $\mathrm{p}$ value for reasons other than treatment of diseases only in both the groups $=0.273$ 


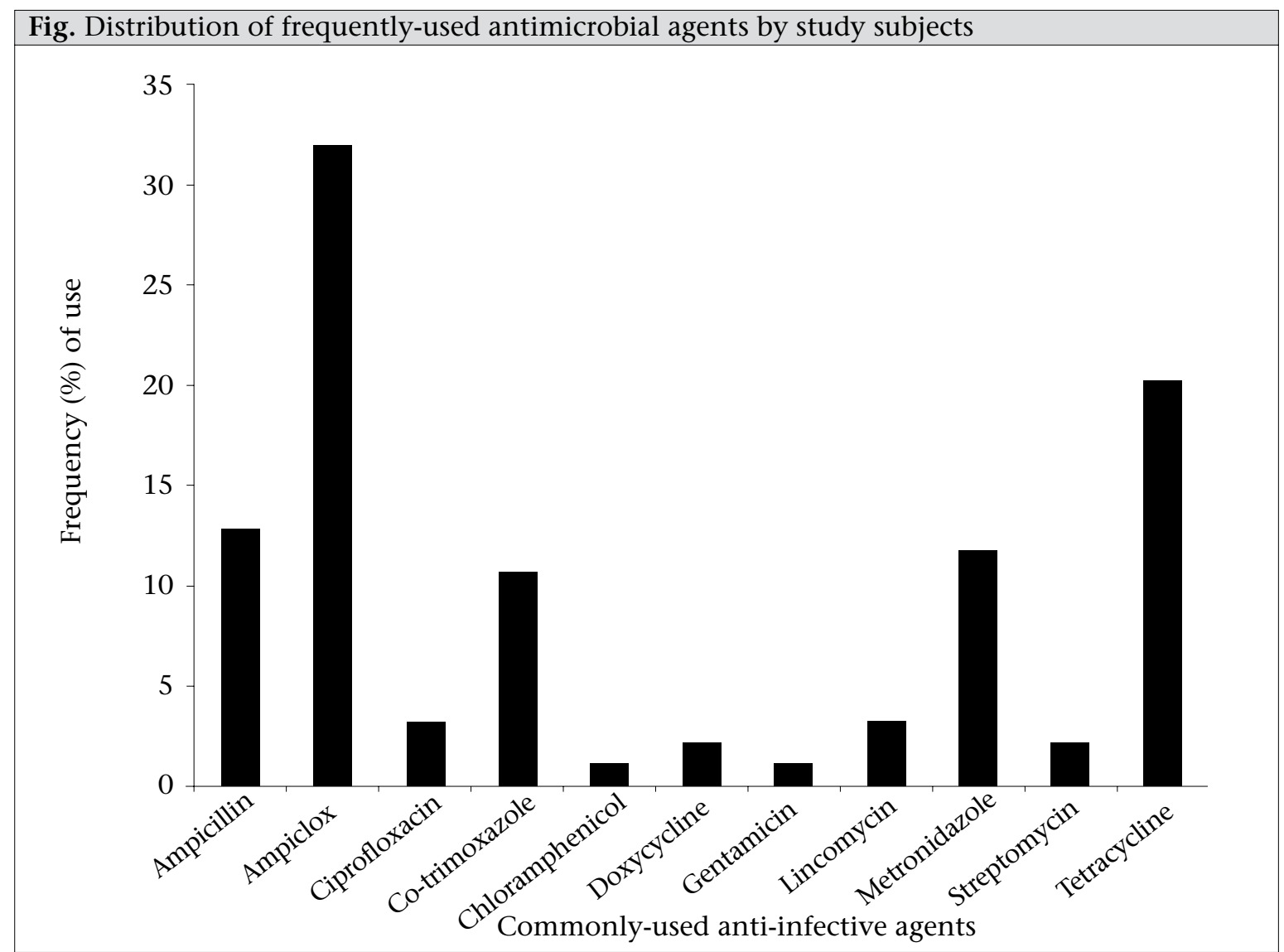

marked difference observed in the multidrug resistance pattern between the isolates from females and those of males in the two groups was not significant ( $\mathrm{p}=0.08$ ) (Table 6).
(12). The increasing prevalence of MRSA infections in communities and hospitals is a global health concern, which necessitates measures to reduce or eradicate the colonization of this strain from

\begin{tabular}{|c|c|c|c|c|}
\hline \multirow{2}{*}{ Pattern } & \multicolumn{2}{|c|}{ Students $(\mathrm{n}=60)$} & \multicolumn{2}{|c|}{ Villagers $(\mathrm{n}=60)$} \\
\hline & No. & $\%$ & No. & $\%$ \\
\hline Stop drugs when symptoms disappear & 17 & 28.3 & 24 & 40.0 \\
\hline Stop when tired of drug & 8 & 13.3 & 11 & 18.3 \\
\hline Take some and leave the rest & 10 & 16.7 & 8 & 13.3 \\
\hline Take all drugs even when symptoms disappear & 25 & 41.7 & 10 & 16.7 \\
\hline Do not complete dose due to financial constraint & 0 & 0.0 & 7 & 11.7 \\
\hline
\end{tabular}

\section{DISCUSSION}

S. aureus remains a versatile and potent pathogen in humans. It is one of the most common causes of nosocomial and community-acquired infections common sites, such as nares. However, the neglect of the gut, an important reservoir of non-pathogenic antibiotic-resistant $S$. aureus strains, can be a source of re-colonization and a potential source of nosocomial infections $(7,13)$.

Table 4. Distribution of intestinal $S$. aureus isolates among study subjects by gender

\begin{tabular}{|lccccc|}
\hline \multirow{2}{*}{ Sex } & No. of & \multicolumn{3}{c}{ No. of $S$. aureus isolates (\%) } & \multirow{2}{*}{ p value } \\
\cline { 2 - 5 } & samples & Students & Villagers & Total & \\
Female & 60 & 12 & 10 & $22(36.6)$ & \\
Male & 60 & 8 & 8 & $16(26.7)$ & \\
Total & 120 & $20(33.3)$ & $18(30.0)$ & $38(31.7)$ & 0.239 \\
\hline
\end{tabular}




\begin{tabular}{|c|c|c|c|c|c|c|c|}
\hline \multirow{3}{*}{ Antimicrobial agent } & \multicolumn{6}{|c|}{ No. of resistant $S$. aureus isolates } & \multirow{3}{*}{$\mathrm{p}$ value } \\
\hline & \multicolumn{2}{|c|}{$\begin{array}{l}\text { Overall } \\
(\mathrm{n}=38)\end{array}$} & \multicolumn{2}{|c|}{$\begin{array}{l}\text { Students } \\
(\mathrm{n}=20)\end{array}$} & \multicolumn{2}{|c|}{$\begin{array}{c}\text { Villagers } \\
(\mathrm{n}=18)\end{array}$} & \\
\hline & No. & $\%$ & No. & $\%$ & No. & $\%$ & \\
\hline Ampicillin $(10 \mu g)$ & 26 & 68.4 & 16 & 80.0 & 10 & 55.6 & 0.106 \\
\hline Augmentin $(30 \mu \mathrm{g})$ & 7 & 18.4 & 3 & 15.0 & 4 & 22.2 & 0.566 \\
\hline Cefuroxime $(30 \mu \mathrm{g})$ & 9 & 23.7 & 7 & 35.0 & 2 & 11.1 & 0.084 \\
\hline Gentamicin $(10 \mu \mathrm{g})$ & 2 & 5.3 & 1 & 5.0 & 1 & 5.6 & 0.939 \\
\hline Ciprofloxacin $(5 \mu \mathrm{g})$ & 3 & 7.9 & 2 & 10.0 & 1 & 5.5 & 0.612 \\
\hline Ofloxacin $(5 \mu \mathrm{g})$ & 3 & 7.9 & 0 & 0.0 & 3 & 16.7 & 0.057 \\
\hline Chloramphenicol $(30 \mu \mathrm{g})$ & 13 & 34.2 & 4 & 20.0 & 9 & 50.0 & 0.052 \\
\hline Co-trimoxazole $(25 \mu \mathrm{g})$ & 14 & 36.8 & 5 & 25.0 & 9 & 50.0 & 0.111 \\
\hline Doxycycline $^{*}(30 \mu \mathrm{g})$ & 23 & 60.5 & 10 & 50.0 & 13 & 72.2 & 0.162 \\
\hline Erythromycin $(15 \mu \mathrm{g})$ & 13 & 34.2 & 8 & 40.0 & 5 & 27.8 & 0.428 \\
\hline Cefoxitin $(30 \mu \mathrm{g})$ & 13 & 34.2 & 5 & 25.0 & 8 & 44.4 & 0.207 \\
\hline Vancomycin $(30 \mu \mathrm{g})$ & 14 & 36.8 & 8 & 40.0 & 6 & 33.3 & 0.671 \\
\hline
\end{tabular}

\begin{tabular}{|c|c|c|c|c|c|c|c|}
\hline \multirow{3}{*}{ Resistance } & \multicolumn{6}{|c|}{ No. of S. aureus isolates (\%) } & \multirow{3}{*}{$\mathrm{p}$ value } \\
\hline & \multicolumn{2}{|c|}{ Females $(n=22)$} & \multicolumn{2}{|c|}{ Males $(n=18)$} & \multicolumn{2}{|c|}{ Total $(n=38)$} & \\
\hline & No. & $\%$ & No. & $\%$ & No. & $\%$ & \\
\hline Fully sensitive & 1 & 4.5 & 2 & 12.5 & 3 & 7.9 & \\
\hline Resistant to 1 agent & 2 & 9.1 & 3 & 18.8 & 5 & 13.2 & \\
\hline Resistant to 2 agents & 2 & 9.1 & 3 & 18.8 & 5 & 13.2 & \\
\hline Resistant to 3 agents & 3 & 13.6 & 2 & 12.5 & 5 & 13.2 & \\
\hline Resistant to 4 agents & 9 & 40.9 & 0 & 0.0 & 9 & 23.7 & \\
\hline Resistant to 5 agents & 1 & 4.5 & 1 & 6.3 & 2 & 5.3 & \\
\hline Resistant to 6 agents & 2 & 9.1 & 1 & 6.3 & 3 & 7.9 & \\
\hline Resistant to 7 agents & 0 & 0.0 & 3 & 18.8 & 3 & 7.9 & \\
\hline Resistant to 8 agents & 1 & 4.5 & 1 & 6.3 & 2 & 5.3 & \\
\hline Resistant to 9 agents & 1 & 4.5 & 0 & 0.0 & 1 & 2.6 & \\
\hline Resistant to 10 agents & 0 & 0.0 & 0 & 0.0 & 0 & 0.0 & \\
\hline Resistant to 11 agents & 0 & 0.0 & 0 & 0.0 & 0 & 0.0 & \\
\hline Resistant to 12 agents & 0 & 0.0 & 0 & 0.0 & 0 & 0.0 & \\
\hline $\begin{array}{l}\text { Resistant to } 3 \text { and } \\
\text { more agents }\end{array}$ & 17 & 77.3 & 8 & 50.0 & 25 & 65.8 & 0.08 \\
\hline
\end{tabular}

The evaluation of antibiotic use among the study subjects revealed that the villagers practised selfmedications of antibiotics and used prescribed antibiotics injudiciously more than the students. The differences were highly significant, which indicate that there are some conditions, such as lack of availability of sufficient health centres with competent personnel, lack of sufficient knowledge on the danger of the wrong use of antibiotics, high proximity to large numbers of unlicensed drug vendors, and high poverty, which predispose them more to the misuse of antibiotic than the students who came from town and cities $(14,15)$. However, the prac- tice of self-medications of antibiotics was generally high (45\%) among all the volunteers. This might be as a result of lack of strict antibiotic control in the country, coupled with the high rate of poverty among the people, which usually hinders them from completing the dosage regimen of antibiotics $(15,16)$.

The distribution of the frequently-used anti-infective agents among the subjects showed that ampicillin, ampiclox, co-trimoxazole, metronidazole, and tetracycline were highly misused. This is due to the fact that these agents are readily available to the people at affordable prices in the country. Thus, 
the excessive use of these agents in an inappropriate dosage regimen will favour the selection of multiple drug-resistant strains that may cause serious infections with limited treatment options (17).

The colonization rate of the gut with $S$. aureus in the study volunteers was observed to be $31.7 \%$. This supports the findings of Bhalla et al., who reported $36.7 \%$ of $S$. aureus intestinal colonization in hospitalized patients as against $50.7 \%$ nasal $S$. aureus in the same patients (18). There are fewer studies on the prevalence of intestinal $S$. aureus compared to nasal, throat, and skin, which may be as a result of the fact that the gut is not being considered an important reservoir of pathogenic staphylococci. However, several recent studies are now implicating this site as an important source of transmission of antibiotic-resistant $S$. aureus-associated infections to the environmental surfaces of communities and hospitals (19-21). Thus, this calls for more studies on the prevalence of intestinal $S$. aureus in Nigeria and other developing countries where proper sanitary systems may be inadequate in rural areas, as a measure to contain its transmission.

The intestinal isolates of $S$. aureus were highly resistant to ampicillin (68.2\%) and doxycycline (60.5\%), with the strains from females significantly showing higher resistant to doxycycline than their male counterparts in both the groups $(p=0.013)$. These observations might be due to the extensive use of these agents as observed while evaluating the use of antibiotics by these subjects. The higher resistance to doxycycline observed among females than among males may be due to the excessive and indiscriminate use of the agent in the treatment of pelvic inflammatory disease (22). Hence, the agents may not be useful in the treatment of infections caused by this organism. Chloramphenicol, erythromycin, and co-trimoxazole, which exhibited moderate activities against the strains of this organism, may be useful in combination therapy against infections due to the organism.

Methicillin resistance in the isolates was observed to be $34.2 \%$, which is in contrast to the findings of Currie et al. and Baba-Mousa et al., who reported $62 \%$ in rectal swabs of hospitalized patients in Canada and $62 \%$ in faecal samples of antibioticassociated diarrhoea patients in Benin respectively $(23,24)$. This marked difference might be due to the varied health status of subjects in the studies. However, the presence of this level of MRSA isolates in stools of these healthy subjects, which exhibited multiple resistances to other agents, is an indication that the gut is an important reservoir of multidrugresistant $S$. aureus. This might predisposes subjects to antibiotic-associated diarrhoea and other community-associated MRSA infections (25).
The number of isolates of $S$. aureus with reduced susceptibility to vancomycin (VISA) was 14 (36. $8 \%$, with $57.1 \%$ of them being MRSA. This is quite higher than findings of Olonitola et al. who reported $2.97 \%$ in nostrils of healthy children in Zaria, Nigeria (26). Vancomycin resistance was first noticed in Enterococcus species which normally colonized the gastrointestinal tract and the co-existence of $S$. aureus with it in the gut might favour the increased emergence of vancomycin-resistant $S$. aureus due to genetic transfer which may account for the observed high prevalence of VISA in this study (27).

The isolates were highly susceptible to cefuroxime, augmentin, ciprofloxacin, ofloxacin, and gentamicin. The observed activities of the stable betalactam antibiotics (cefuroxime and augmentin) might be due to their intrinsic characteristics, of being resistant to the beta-lactamases of the organism, coupled with their low level of misuse in the community. $S$. aureus isolates from other sites have been widely reported to be highly susceptible to fluoroquinolones and gentamicin $(28,29)$, which is equally observed in this study. This makes these agents the appropriate drugs of choice in the empirical treatment of most infections caused by this organism since most MRSA and VISA isolates in this study were susceptible to them.

This study reports a high (65.8\%) level of multiple antibiotic resistance in intestinal $S$. aureus isolates from the healthy adults, with those from the females higher than the males. Previous studies on other sites of healthy individuals reported a similar high prevalence of multiple antibiotic resistance in $S$. aureus $(28,30)$. This suggests the possibility of having infections due to $S$. aureus with limited treatment options. Hence, there is a need to adopt measures of eradicating and preventing the transmission of this organism to vulnerable populations, especially in women who play a vital role in the transmission.

\section{Conclusions}

The results of this study emphasize the importance of the gut as a reservoir and a source of transmission of multiple antibiotic-resistant strains of $S$. aureus which might lead to more severe infections. Hence, there is a need to adopt strategies to encourage proper personal hygiene and provide adequate effective sewage-disposal systems that will prevent the transmission of these strains to our environments. Also, the need to control the excessive use and misuse of antibiotics as a means of curbing the increasing rate of antibiotic resistance in this country cannot be overemphasized. 


\section{REFERENCES}

1. Weems JJ. The many faces of Staphylococcus aureus infection. Recognizing and managing its life-threatening manifestations. Postgrad Med 2001;110:24-6, 29-31, 35-36.

2. Lowy FD. Antimicrobial resistance: the example of Staphylococcus aureus. J Clin Invest 2003;111:1265-73.

3. Chamber HF. Community-associated MRSAresistance and virulence converge. New Engl J Med 2005;352:1485-7.

4. Okeke IN, Lamikanra A. Export of antimicrobial drugs by West African travellers. J Travel Med 2003; 10:133-5.

5. Andargie G, Kassu A, Moges F, Tiruneh M, Huruy K. Prevalence of bacteria and intestinal parasites among food-handlers in Gondar town, northwest Ethiopia. J Health Popul Nutr 2008;26:451-5.

6. Boyce JM, Havill NL. Nosocomial antibiotic-associated diarrhea associated with enterotoxin-producing strains of methicillin-resistant Staphylococcus aureus. Am J Gastroenterol 2005;100:1828-34.

7. Domínguez E, Zarazaga M, Torres C. Antibiotic resistance in Staphylococcus isolates obtained from fecal samples of healthy children. J Clin Microbiol 2002; 40:2638-41.

8. Boyce JM, Havill NL, Otter JA, Adams NM. Widespread environmental contamination associated with patients with diarrhea and methicillin-resistant Staphylococcus aureus colonization of the gastrointestinal tract. Infect Control Hosp Epidemiol 2007;28:1142-7.

9. Clinical and Laboratory Standard Institute. Performance standards for antimicrobial susceptibility testing. 18th informational supplement. M100-S18. Wayne, PA: Clinical and Laboratory Standard Institute, 2008; 28:46-52.

10. Cheesbrough M. District laboratory practice in tropical countries. P. 2. Cambridge: Cambridge University Press, 2002:136-42.

11. British Society for Antimicrobial Chemotherapy. Disc diffusion method for antimicrobial susceptibility testing. British Soc Antimicrob Chemother 2002;(2.1.2):146.

12. Rajbhandari R, Manandhar SP, Shrestha J. Comparative study of MRSA and its antiboitic susceptibility pattern in indoor and outdoor patients of Bir Hospital. Nepalase J Microbiol 2003;1:62-5.

13. de Jong E. Effects of selective decontamination of digestive tract on mortality and antibiotic resistance in the intensive-care unit. Curr Opin Crit Care 2005; 11:144-9.

14. McNulty CA, Boyle P, Nichols T, Clappison P, Davey P. The public's attitudes to and compliance with antibi- otics. J Antimicrob Chemother 2007;60(Suppl 1):i638.

15. Pechère JC. Patients' interviews and misuse of antibiotics. Clin Infect Dis 2001;33(Suppl 3):S170-3.

16. Okeke IN, Edelman R. Dissemination of antibioticresistant bacteria across geographic borders. Clin Infect Dis 2001;33:362-9.

17. Okeke IN, Laxminarayan R, Bhutta ZA, Duse AG, Jenkins $\mathrm{P}, \mathrm{O}^{\prime}$ Brien TF et al. Antimicrobial resistance in developing countries. Part I: Recent trends and current status. Lancet Infect Dis 2005;5:481-93.

18. Bhalla A, Aron DC, Donskey C J. Staphylococcus aureus intestinal colonization is associated with increased frequency of $S$. aureus on skin of hospitalized patients. BMC Infect Dis 2007;7:105-12.

19. Squier C, Rihs JD, Risa KJ, Sagnimeni A, Wagener MM, Stout J et al. Staphylococcus aureus rectal carriage and its association with infections in patients in a surgical intensive care unit and a liver transplant unit. Infect Control Hosp Epidemiol 2002;23:495-501.

20. Donskey CJ. The role of the intestinal tract as a reservoir and source for transmission of nosocomial pathogens. Clin Infect Dis 2004;39:219-26.

21. Boyce JM, Havill NL, Maria B. Frequency and possible infection control implications of gastrointestinal colonization with methicillin-resistant Staphylococcus aureus. J Clin Microbiol 2005;43:5992-5.

22. Nester EW, Anderson DG, Roberts CE, Pearsall NN, Nester MT. Genitourinary infections. In: Nester EW, Anderson DG, Roberts CE, Pearsall NN, Nester MT. Microbiology: a human perspective. 4th ed. New York, NY: McGraw-Hill, 2004:645-6.

23. Currie A, Davis L, Odrobina E, Waldman S, White D, Tomassi J et al. Sensitivities of nasal and rectal swabs for detection of methicillin-resistant Staphylococcus aureus colonization in an active surveillance program. J Clin Microbiol 2008;46:3101-3.

24. Baba-Moussa L, Ahissou H, Azokpota P, Assogba B, Atindéhou MM, Anagonou S et al. Toxins and adhesion factors associated with Staphylococcus aureus strains isolated from diarrhoeal patients in Benin. Afr J Biotech 2010;9:604-11.

25. Tacconeli E, De Angelis G, Cataldo MA, Pozzi E, Cauda R. Does antibiotic exposure increase the risk of methicillin-resistant Staphylococcus aureus (MRSA) isolation? A systematic review and meta-analysis. $J$ Antimicrob Chemother 2008;61:26-38.

26. Olonitola OS, INabo HI, Olayinka BO, Bugo ID. Nasal carriage of methicillin-resistant Staphylococcus aureus by primary school pupils in a university staff school, Zaria, Nigeria. Int J Biol Chem Sci 2007;1:71-5. 
27. Ray AJ, Pultz NJ, Bhalla A, Aron DC, Donskey CJ. Coexistence of vancomycin-resistant enterococci and Staphylococcus aureus in the intestinal tracts of hospitalized patients. Clin Infect Dis 2003;37:875-81.

28. Onanuga A, Oyi AR, Olayinka BO, Onaolapo JA. Prevalence of community associated multi-resistant Staphylococcus aureus among healthy women in Abuja, Nigeria. Afr J Biotech 2005;4:942-5.
29. Oguzkaya-Artan M, Baykan Z, Artan C. Nasal carriage of Staphylococcus aureus in healthy preschool children. Ipn J Infect Dis 2008;61:70-2.

30. Jayaraman S, Manoharan M, Illanchezian S, Sekher $\mathrm{R}$, Sathyamurthi P. Plasmid analysis and prevalence of multidrug resistant Staphylococcus aureus reservoirs in Chennai city, India. Internet J Microbiol 2009;7:112. 